\title{
Intertrial reinforcement as interference with consolidation '
}

HAROLD LOBB AND DENNIS RUNCIE UNIVERSITY OF WESTERN ONTARIO

Intertrial reinforcement was administered to rats during acquisition of a locomotor response with $50 \%$ reward. If the time interval between nonreward and intertrial reinforcement were only $15 \mathrm{sec}$, no PRE was subsequently observed in the extinction phase, whereas if the interval were $60 \mathrm{~min}$, the PRE appeared undiminished. These findings are compatible with the theory that the capacity of intertrial reinforcement to eliminate the effects of nonreward is an inverse function of the degree of prior consolidation of the classically conditioned frustration response.

In a reformulation of the Hull-Sheffield theory of the partial reward effect (PRE) on extinction, Capaldi (1966) has postulated stimulus aftereffects or memories of reward and nonreward ( $\mathrm{S}^{\mathrm{R}}$ and $\mathrm{S}^{\mathrm{N}}$ ) that are "long lived" but readily "replaceable." For example, occurrence of reward (R) more or less completely obliterates any prior $\mathrm{SN}$ and replaces it with $\mathrm{SR}$, regardless of the time interval between nonreward (N) and $R$. Such mutual replaceability is a basic assumption in the revised theory.

Other Hullian theorists (e.g., Amsel, 1958; Spence, 1960) have continued to view $R$ and $N$ as stable learning situations. In their models noncontinuous reward provides for acquisition of anticipations of reward $\left(r_{R^{-8}}\right)$ and nonreward $\left(r_{F^{-S}}\right)$, according to principles of classical conditioning at the goal. These anticipations have the status of hypothetical responses, which do not become active until evoked by appropriate stimuli. Moreover. classical conditioning is presumed to be incremental, and associations resulting from a single trial a re not ordinarily eliminated by subsequent occurrence of an inverse experience. Thus, the anticipatory goal response mechanism would require fundamental revisions, were Capaldi's theory to gain broad experimental support.

An implication of the replaceability notion in the Capaldi theory is that little or no PRE should be observed during extinction after partial reward training, if $\mathrm{N}$ has never adjacently preceded a trial on which the instrumental response was rewarded. In brief, the procedure employed to fulfill these conditions has been to place the animal in a box similar to the goalbox after removal on an $N$ trial. In the alternate box $S$ gets the regular $R$, supposedly replacing $S^{N}$ with $S^{R}$. Consequently, $\mathrm{S}^{\mathrm{N}}$ cannot become conditioned to the instrumental response on the next rewarded trial. This procedure is called "Intertrial reinforcement" (ITR).

Apparently, in all ITR investigations reported to date (e.g., Black \& Spence, 1965; Capaldi \& Spivey, 1964; Spence, Platt, \& Matsumoto, 1965), the time interval between removal from the nonrewarded goalbox and placement in the rewarding box has not exceeded about 15 sec. In these experiments the PRE was attenuated, unless partial reward training wasprolonged.However, it is likely that 15 sec did not allow sufficient time for consolidation of $r_{F}-8$, when followed by the opposite (R) event (see McGaugh, 1966). In other words, the ITR effect may represent not the replacement of stimulus memory, but interference during a stage of learning. The following experiment was conducted to evaluate the consolidation hypothesis, by varying the time interval between $\mathbf{N}$ and ITR.

\section{Method}

Ss were 60 male albino rats (Sprague-Dawley), about 100 days old at the start of the experiment. One died during the study. Locomotor response was measured in one of a pair of parallel runways, proceeding from a $\mathrm{Y}$-shaped choice area in which one arm was blocked. The general dimensions of the apparatus were the same as described by Logan (1960). Over the final $4 \mathrm{ft}$ the alley was straight, $3 \mathrm{in}$. wide, and covered with Plexiglas lids. Its walls were flat gray behind Plexiglas. Four sheet-metal gates were electronically controlled to regulate entrance to the startbox and alley, and to prevent retracing from the alley and goalbox. The two goalboxes consisted of the terminal $15 \mathrm{in}$. of each alley, both containing a foodcup that protruded Inwards $3 / 4$ in. through the end of the alley. Internally the two goalboxes were identical. Photobeams divided the alley into $1-\mathrm{ft}$ segments and controlled electric clocks, which measured locomotor time (.01 sec) in successive segments.

Ss were kept in individual cages. During the first 20 days they were habituated to eat $12 \mathrm{~g}$ Fox meal mixed with $12 \mathrm{~g}$ water daily at a fixed time. Water bottles were avallable for $30 \mathrm{~min}$ after the mash was placed in the cages. This feeding schedule was maintained throughout the experiment. Ss were also induced to drink $1 \mathrm{ml}$ of $32 \%$ sucrose solution in the home cage. During habituation each animal was allowed $5 \mathrm{~min}$ to explore the alley with all gates open, and received one direct placement to drink $.7 \mathrm{ml}$ of the sucrose from the goalbox foodcup.

Acquisition began with $12 \mathrm{R}$ trials for all $\mathrm{Ss}$ at the rate of two trials per day, about $1 \mathrm{~h}$ apart. On every trial $\mathrm{S}$ was taken from his cage, placed in the entrybox, and then allowed access to the startbox after E reset the clocks. Two sec later the starting gate was opened. On all $\mathbf{R}$ trials, $\mathrm{S}$ found $.7 \mathrm{ml}$ of $32 \%$ sucrose in the foodcup. Following ingestion of the fluld, Swas removed to the home cage. About $30 \mathrm{~min}$ later it was given food and water.

Experimental treatments for the next stage of training varied according to a 3 by 2 factorial design. The first factor was defined jointly by reward schedule and the type of trial that ITR followed: $50 \% \mathrm{R}$ and ITR after every $R\left(P_{R}\right) ; 50 \% R$ and ITR after every $N\left(P_{N}\right) ; 100 \%$ $R$ and ITR after half the $R s(C)$. The other factor was the time period between removal from one goalbox and 
placement into the other for ITR, either $15 \mathrm{sec}$ or 60 min. The six treatments are symbolized: $P_{R .25}, P_{N .25}$, $C_{.25} ; P_{R 60}, P_{N 60}, C_{60}$. Ten Ss were randomiy assigned to each condition. All received one trial per day. $\mathrm{R}$ trials were the same as described above. An identical procedure was used for $\mathrm{N}$ trials, except that the foodcup was empty and goalbox confinement was 15 sec. $S$ was then taken to the home cage, and about $1-1 / 2 \mathrm{~h}$ later it received food and water. During the interim at the scheduled time on half of the days, every $S$ was taken for ITR to the alternate goalbox and placed directly in front of the foodcup, which contained $.7 \mathrm{ml}$ of $32 \%$ sucrose. After drinking it, $S$ was returned to its cage. Twenty trials were given, in which the partial reward sequence was RNRNNRRNNRRNNNRRRNNR (Wagner, 1961).

Extinction trials started on the next day. Twenty trials were given at the rate of one per day. The procedure was the same as for $\mathrm{N}$ trials, omitting ITRs.

Results

Extinction data are considered for the final $4 \mathrm{ft}$ of the alley, as there were no significant differences between groups in Segment 1. Graphical patterns were similar in the four segments, and, for the sake of brevity, speed (ft/ sec) across the whole $4 \mathrm{ft}$ was used as the response measure. S's median speed per block of four extinction trials was taken as the criterion for analysis. A 3 by 2 analysis of variance was computed on the separate blocks. It showed no significant effects on Block 1, but thereafter the three-level factor of reinforcement schedule was significant $(p<.01)$. Extinction curves of the sixgroups are plotted in Fig. 1. They suggest a PRE with Groups $P_{R 60}, P_{N 60,} P_{R .25}$, but little or none with $P_{N .25}$.

The performance of individual groups was examined in Blocks 2-5 by comparing each $P$ group mean against its own control (C), using the error terms from the analyses of variance and the proper t table. Table 1 contains the results of these tests. It shows that the PRE was about as persistent in Group $\mathrm{P}_{\mathrm{N} 60}$ as in $\mathrm{P}_{\mathrm{R} 60}$. The PRE was demonstrated to a lesser extent with $P_{R .25}$, mainly because the other $C$ group was involved in this set of comparisons. Group $\mathrm{P}_{\mathrm{N} .25}$ alone failed to show a reliable effect of partial reward training. Even when com-

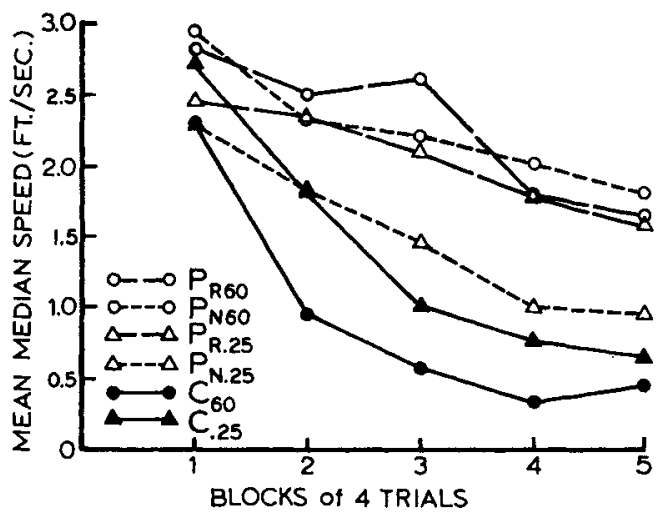

Fig. 1. Average locomotor speed of each group while traversing the final $4 \mathrm{ft}$ of the alley during extinction training.
Table 1

Results of comparing each $P$ group mean against its own control

\begin{tabular}{|c|c|c|c|c|c|c|c|c|}
\hline \multicolumn{9}{|c|}{ Block } \\
\hline \multirow[t]{2}{*}{ Group } & \multicolumn{2}{|c|}{2} & \multicolumn{2}{|c|}{3} & \multicolumn{2}{|c|}{4} & \multicolumn{2}{|c|}{5} \\
\hline & $\mathbf{t}$ & $\mathrm{p}$ & $\mathbf{t}$ & $p$ & $t$ & $\mathrm{p}$ & $\mathbf{t}$ & $p$ \\
\hline $\mathbf{P}_{\mathbf{R} 60}$ & 4.72 & $<.01$ & 4.64 & $<.01$ & 3.28 & $<.01$ & 2.62 & $<.05$ \\
\hline $\mathbf{P}_{\mathrm{N} 60}$ & 3.34 & $<.01$ & 3.70 & $<.01$ & 3.78 & $<.01$ & 2.98 & $<.02$ \\
\hline $\mathbf{P}_{\mathbf{R} .25}$ & 1.24 & $>.10$ & 2.50 & $<.05$ & 2.26 & $\approx .05$ & 1.81 & $>.10$ \\
\hline $\mathbf{P}_{\mathrm{N} .25}$ & .01 & $>.10$ & 1.06 & $>.10$ & .53 & $>.10$ & .64 & $>.10$ \\
\hline
\end{tabular}

pared to $\mathrm{C}_{60}$, it was not significantly faster on any block. Discussion

The close correspondence between the extinction performance of Groups $P_{\mathrm{N} 60}$ and $P_{\mathrm{R} 60}$ indicates that interpolation of $60 \mathrm{~min}$ between every nonreward trial and the ITR virtually eliminated any detrimental effect of the latter on the PRE. This fact, together with the reverse finding for $\mathrm{P}_{\mathrm{N} .25}$, signifies that a time span of $1 \mathrm{~h}$ probabily encompasses the complete range from total replacement of $\mathrm{S}^{\mathrm{N}}$ to no replacement of $\mathrm{S}^{\mathrm{N}}$ within our conditions. The results are entirely consistent with the assumption that $R$ interferes with consolidation of $r_{F}$ $-{ }_{-5} \mathrm{~F}$ during a critical, but relatively short period of time after the $\mathrm{N}$ event. On the other hand, the data suggest that labile concepts of $S^{N}$ and $s^{R}$ have limited utility in explaining the PRE.

As previously mentioned, studies (Black \& Spence, 1965; Spence, Platt, \& Matsumoto, 1965) have shown that a PRE can be obtained despite 15-sec ITRs when partial reward training is prolonged. It should be noted that in these experiments not every $\mathrm{N}$ trial was followed by ITR, and it is possible that the PRE was primarily due to the conditioning of frustration on the $\mathrm{N}$ trial not followed by ITR. In the present experiment extinction took place after a partial reward series that included just 10 trials of $N$ plus ITR. Attainment of the PRE with such little training attests to the overriding importance of the time interval separating $\mathbf{N}$ from ITR as a determinant of the PRE.

\section{References}

AMSEL, A. The role of frustrative nonreward in noncontinuous reward situations. Psychol. Bull, 1958, 55, 102-119.

BLACK, R. W., \& SPENCE, K. W. Intertrial reinforcement and extinction. J. exp. Psychol, 1965, 70, 559-563.

CAPALDI, E. J. Partial reinforcement: A hypothesis of sequential effects. Psychol. Rev., 1966, 73, 459-477.

CAPALDI, E. J., \& SPIVEY, J. E. Intertrial reinforcement and aftereffects at 24hour intervals. Psychon. Sci, 1964, 1, 181-182.

McGAUGH, J. L. Time-dependent processes in memory storage. Science, 1966, 153, 1351-1358.

LOGAN, F. A. Incentive. New Haven: Yale University Press, 1960.

SPENCE, K. W. Behavior theory and learning: selected papers. Englewood Cliffs: Prentice-Hall, 1960.

SPENCE, K. W., PLATT, J. R., \& MATSUMOTO, R. Intertrial reinforcement and partial reinforcement effect as a function of number of training trials. Psychon. Sci, 1965, 3, 205-206.

WAGNER, A. R. Effects of amount and percentage of reinforcement and number of acquisition trials on conditioning and extinction. $J$. exp. Psychol, 1961, 62, 234242.

Note

1. This article is based on an experiment conducted for an MA thesis by the second author under supervision of the first author. We thank Drs. G. Mogenson, A. Monjan and M. Russek for advice concerning the physiology of conditioning. 